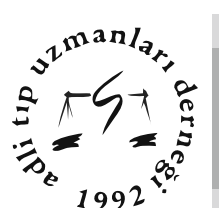

1992

\title{
İş Kazasına Bağlı Ölüm: İki Olgu Sunumu
}

\author{
Death due to Occupational Accident: A Report of Two Cases \\ Celal Bütün, Fatma Yücel Beyaztaș, Sema Yaman, Adem Artar, Oğuzhan Öğüt
}

Cumhuriyet Üniversitesi Tıp Fakültesi Adli Tıp Anabilim Dalı, Sivas, Türkiye

\section{Özet}

Günümüzdeki hızlı teknolojik gelişmeler, çalışanların sağlığına ve iş güvenliğine yönelik tehlikeleri de arttırmaktadır. Çalışma ortamında gerekli güvenlik önlemlerinin alınmaması, hatalı davranışlar, kişisel yetenekler, teknik arızalar gibi nedenlerle ortaya çıkan iş kazaları yaralanma, iş gücü kaybı, sakatlık ya da ölümlerle sonuçlanmaktadır. Dolayısıyla iş kazaları adli tıbbın önemli bir alanını oluşturmaktadır.

Bu çalışmada: krom üretimi yapan maden ocağında aynı alanda iş kazası sonucu ölüm meydana gelen 27 ve 39 yaşlarında iki erkek olgu ele alındı. Ölü muayenesi, adli otopsi ve postmortem tetkikler yapılan olgularda olaya bağlı bulguların benzer olması nedeniyle birlikte değerlendirildi. Dış muayenede yüz bölgesi ve boyun ön yüzün siyanotik görünümde olup skleraların hiperemik olduğu, otopsilerinde cilt altında ve organ yüzeylerinde yer yer noktasal kanamalar olduğu, postmortem histopatolojide beyinde subaraknoidal alanda ekstravaze eritrositler, akciğerlerde plevral alanda kanama, midede ekstravaze eritrositler ve submukozal alanda kanama, konjesyon olduğu saptandı. Ölüm nedeninin oksijen yetersizliğine bağlı gelişen asfiksi olduğu sonucuna varıldığı,

$\mathrm{Bu}$ çalışmada; iş kazasına bağlı yaralanma ve ölümlerin ülkemizdeki görülme oranlarının yüksekliği de göz önünde bulundurularak iş kazasına neden olan bireysel, sosyo-ekonomik ve çevresel etmenlerin saptanması, iş kazalarının önlenmesine yönelik alınması gerekli tedbirlerin öneminin vurgulanması ve iş kazası olgularına adli tıbbi yaklaşımın literatür eşliğinde tartışılması amaçlandı.

Anahtar kelimeler: Adli tıp, İş kazası, Ölüm, Asfiksi, Otopsi.

\section{Giriş}

Uluslararası Çalışma Örgütü'nün (ILO) tanımına göre iş kazası, zarara ya da yaralanmaya neden olan, beklenmedik bir zamanda oluşan ve önceden planlanmamış bir olay (1) olup; çalışanların gördükleri iş nedeniyle makine veya insan kaynaklı olarak maruz kaldıkları tehlikeler yüzünden oluşan maddi ve manevi kayıplarla sonuçlanan olaylardır (2).

Günümüzde üretimin ve rekabetin büyük ölçüde artması ile teknolojideki hızlı gelişmeler, çalışanların sağlığına ve iş güvenliğine yönelik tehlikeleri de arttırmaktadır. Sanayileşme ile birlikte hemen hemen her iş kolunda fiziksel, kimyasal ve toksikolojik nedenler çalışanların zarar görmesine hatta

Sorumlu Yazar: Yrd. Doç Dr. Celal Bütün

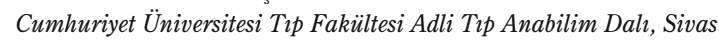

E-mail: celalbutun@yahoo.com

\section{Abstract}

Today's rapid technological developments increase, also the risks to worker's health and work safety. Occupational accidents occurred with reasons such as necessary safety measures in work environment, incorrect behavior, inability on personal skills, technical failures result in bodily injury, loss of labor, disability or death.

In this study; two male death cases aged 27 and 39 years occurred as a result of occupational accident in the area at the chrome mines were discussed. On the cases, physical examination, forensic autopsy and post-mortem examinations were performed. Event-related findings are similar; the cases were evaluated, together. It was determined that, respectively, cyanotic appearance on facial area and the front of the neck, the hyperemia on the sclera during external body examinations; in places punctuated hemorrhages under the skin and on the visceral organs' surfaces during the autopsies; hemorrhage in subarachnoidal area of the brain, hemorrhage on pleural areas of the lungs, sub-mucosal bleeding and congestion in the stomach during the post-mortem histopathology. Finally, the death cause of cases was due to lack of oxygen.

In this study; also taking into account of work accident related injuries and deaths seen high rates in our country, the determination of personal, socio-economic and environmental factors and, the importance of taking the necessary measures for prevention of occupational accident were emphasized. Also, it aimed to be discussed forensic medical approach to occupational injury cases in the literature.

Keywords: Forensic medicine, Occupational accident, Asphyxia, Death, Autopsy.

ölümlere yol açmaktadır. Çalışma ortamında gerekli güvenlik önlemlerin alınmaması, hatalı davranışlar, kişisel yetenekler, teknik arızalar gibi nedenlerle ortaya çıkan iş kazaları yaralanma, iş gücü kaybı, sakatlık ya da ölümlerle sonuçlanmaktadır. Dolayısıyla iş kazaları adli tıbbın önemli bir alanını oluşturmaktadır $(3,4)$.

$\mathrm{Bu}$ çalışmada; iş kazasına bağlı yaralanma ve ölümlerin ülkemizdeki oranları da göz önüne alındığında iş kazasına neden olan bireysel, sosyoekonomik değişkenler ile işyeri ve işverenle ilgili etmenlerin saptanması, ayrıca kazaların önlenmesi için alınması gerekli tedbirlerin vurgulanması amaçland1.

\section{Olgu Sunumu}

\section{Olgu 1}

Maden ocağında iş kazası sonucu öldüğü bildirilen 27 
yaşında erkek olgunun harici muayenesinde; gözlerde skleraların hiperemik, ağızda dudak mukozaları, kulaklar, boyun yanlar ve gögüis üst kısımların yoğun mor-kırmızı görünümde olduğu, gövde arkasında sol skapula altından başlayıp sol lomber bölgeye uzanan 5x6 cm'lik sıyrıklı ekimotik alan, torakolomber hattın sağında 5-6 cm'lik sıyrık olduğu, sağ arka aksiller hat boyunca $18 \mathrm{~cm}$ 'lik kırmızı renkli sıyrıklı ekimoz, sağ dirsek diş yanda 1x2,5 cm'lik sıyrık görüldüğü, sağ koltuk altında yatay ve kısmen oblik seyirli, meme bașı hattı ile kesişme bölgesinde $16 \mathrm{~cm}$ 'lik, bunun $5 \mathrm{~cm}$ altında $3 \mathrm{~cm}$ 'lik ve son kostalar hizasının arka koltuk altı ile kesişme bölgesinde 4 cm'lik çizik tarzında sıyrıklı ekimoz olduğu, sol dirsek arka yüzünde $6 x 5$ cm'lik kısmen oval şekilli sıyrıklı ekimoz olduğu, otopside; saçlı deri altının açık kırmızı görünümde olup noktasal kanamalar olduğu, beyin ve beyincik yüzeylerinin yaygın hiperemik, konjesyone görünümde ve ödeme bağlı düzleşmiş olduğu, göğüs deri altının açık kırmızı renkte olduğu, her iki akciğerin yer yer antrakotik alanlar da içeren yaygın mor-kırmızı görünümde olduğu, akciğer yüzeylerinde ve lob aralarında noktasal kanamalar olduğu, bronşlar açıldığında bronş mukozasının hiperemik ve kanamalı olduğu, kalp haricen değerlendirildiğinde sağ ventrikül alt yüzünde noktasal kanamalar olduğu, boyun organlarının incelenmesinde trakea mukozasının hiperemik ve yer yer kanamalı olduğu, mide açılarak incelendiğinde $2 / 3$ proksimal bölümünde yaygın submukozal kanama alanları tespit edildiği, ince bağırsakların yaygın sarı yeşil renkte ve mukozasının hiperemik görünümde olduğu, pankreasın yaygın kanamalı görünümde olduğu, her iki böbrek yüzeyleri düzgün olup yüzey ve kesitlerinin ileri derecede konjesyone görünümde oldukları tespit edilmiştir.

Histopatoloji raporunda; beyinde subaraknoidal alanda az sayıda ekstravaze eritrositler izlendiği, akciğerde alveoler ödem ve eritrositler, bronş lümeninde eritrositler, amfizematöz değişiklikler, alveoler makrofajlar, antrakoz, konjesyon, plevral alanda kanama bulgusu izlendiği, mide mukozasında otoliz bulgusu, belirgin konjesyon, ekstravaze eritrositler ve submukozal alanda kanama, konjesyon izlendiği, toksikoloji raporunda; mide içeriği, kan ve idrarda sistematikteki toksikolojik maddelerin ve HbCO'in (karboksi-hemoglobin) saptanmadığı kayıtlıdır.

\section{Olgu 2}

Aynı maden ocağında iş kazası sonucu öldüğü bildilen 39 yaşında erkek olgunun harici muayenesinde; ölü lekelerinin sirtta, belde ve ekstremite ön yüzlerde bası görmeyen yerlerde yoğun mor renkte meydana geldiği, sol dudak mukozaları, kulaklar, boyun yanlarda yoğun mor renk görünümünde olduğu, kafada sol frontalde kaş orta hat üstünde $2,5 \mathrm{x} 0.5 \mathrm{~cm}$ 'lik ekimoz ve bunun hemen üzerinde $1 x 1 \mathrm{~cm}$ 'lik oblik seyirli sıyrıklı ekimoz ile sol kaş lateralinde $0.5 x 0.5$ cm'lik sıyrıklı alan olduğu, gözlerde skleralar hiperemik görünümde, sternum alt yarısında birbirine paralel dikey seyirli aralarında $1 \mathrm{~cm}$ mesafe bulunan 4 ve $5 \mathrm{~cm}$ uzunluklarında iki adet mor renkli ekimozlu hatlar olduğu, lumbosakral bölgede 2x1 cm'lik yüzeyel sıyrıklı ekimotik alan, üst ekstremitelerde sol el bilek dış yanda $0.5 \times 0.5$ cm'lik sıyrıklı alan, sağ el sırtında 2., 3. ve 4. metakarp proksimaline uyan bölgede $3 \times 1 \mathrm{~cm}$ 'lik mor renkli ekimoz olduğu, sağ diz önünde 0.5 cm'lik sıyrık olduğu, otopside; saçlı deri altında özellikle pariyetooksipital bölgelerde noktasal kanamalar ve deri altının açık kırmızı görünümde olduğu, beyin yüzeyleri yaygin hiperemik, konjesyone görünümde ve düzleşmiş, sulkuslarının silinmiş olduğu, beyinde frontopariyetal alanlarda yer yer yüzeyel kırmızı renkli kanamalı alanlar görüldüğü, göğüs deri altının açık kırmızı renkte ve interkostal kasların yaygın parlak kırmızı renkte olduğu, her iki akciğerin antrakotik alanlar da içeren yaygın mor kırmızı renkte oldukları, lob aralarında ve diyafragmatik yüzeylerde yer yer noktasal kanamalar içerdikleri, bronşlar açıldığında bronş mukozasının yer yer kanamalı olduğu, ayrıca mukozaların köpüklü ve kırmızı sıvı ile sıvalı bulunduğu, her iki akciğer kesitlerinin yaygın koyu kırmızı renkte olduğu ve sıkmakla bol kanlı köpüklü sıvı geldiği, boyun organlarında trakea açıldığında mukozanın hiperemik ve yer yer kanamalı olduğu, batında karaciğer üst yüzeylerinde büyüklükleri 0.5-1 cm arasında değişen beş adet koyu kırmızı-siyah renkli kapsül altı kanamalar olduğu, mide mukozası incelendiğinde fundusta mukozanın vişne çürüğü renginde ve ayrıca mukozanın incelmiş görünümde olduğu, midede korpusta peteşiyal kanamalar olduğu saptanmıştır.

Histopatoloji raporunda; beyinde subaraknoidal alanda az sayıda ekstravaze eritrositler izlendiği, akciğerde otoliz bulguları, alveoler ödem ve eritrositler, amfizematöz değişiklikler, antrakoz, makrofajlar, konjesyon izlendiği, kalpte myokardiyal kesitlerde intertisyel-perivasküler fibrozis, fokal ekstravaze eritrositler, mide mukozasinda otoliz bulguları olduğu, toksikoloji raporunda; mide içeriğinde, kan ve idrarda sistematikteki maddelerin, ayrıca HbCO'in bulunmadı̆̆ 1 kayıtlıdır.

Adli dosya incelemesinde; olguların çalıştığı maden ocağının krom üretimi yapan yer altı ocağı olduğu, kuyu ve galeri ile üretim yapan bu işletmede kuyudan açılmış 20, 40, 60, 80, 110, 130 kot (seviye) diye adlandırılan ana galeriler bulunduğu, ocak içi nakliyenin ray-vagon sistemi ile yapıldığı, madenin kuyu-asansör sistemi ile ocak dışına çıkarıldığı, bir adet elektrikli kompresör ve bir adet motorin ile çalışan kompresörün ocak içerisine basınçlı hava pompalamasıyla ocaktaki havalandırmanın sağlandığı, kirli havanın ana galeri ve ferelerden yeryüzüne çıktığı, ocak içerisindeki havanın 
sadece insan tüketimi ile kirlendiği belirtilmiştir. Ayrıca bu olgular diğer işçilerin yanına gelmeyince olguları kontrol için 56 işçinin söz konusu kot bölümüne doğru yaklaştıkça ortamdaki oksijen yetersizliğini gösteren bayılma, düşme gibi belirtilerin ifade edildiği, dolayısıyla bu olguların bulunduğu bölüme ulaşamadıkları ve hastaneye tedavileri için gönderildikleri, ayrıca olaydan on gün önce bu bölgedeki çalışmanın durdurulduğu, dolayısıyla havalandırmanın yapılmadığı ve sözlü olarak bu bölgeye gidilmemesi gerektiği bildirildiği ancak buraların insan girişine engel olacak şekilde kapatılmadı̆̆ ocağının "nefeslik" adı verilen bölümünde yer üstü sularının toplandığı, havuza çok yakın bir mesafede olduğu ve üst kademelerden akan toprak ve posa sebebi ile kapanma riski altında olduğu, olay sonrası hava ölçüm cihazı ile yapılan ölçümlerden olay bölgesi olan 110. kot sıçrama bölümünde (yaklaşık 110 metre derinlikte) oksijen yetersizliği tespit edilmiştir.

Sonuç olarak, ölüm nedenlerinin asfiksiye bağlı oksijen yetmezliği (hipoksi) sonucu olduğu kanaatine varılmıştır.

\section{Tartışma ve Sonuç}

İş sağlığ 1 ve güvenliği; tüm dünyada önemli bir konu olarak ele alınmakla birlikte, her yıl azımsanmayacak kadar insan, engellenebilecek olan iş kazası sonucu yaşamını yitirmektedir. Bunun sonucu olarak adli tıp uygulamalarında iş kazalarına bağlı meydana gelen yaralanma ve ölümlerle sıkça karşılaşılmaktadır (5).

Dünya genelinde hiç de az olmayan sayıda meydana gelen iş kazaları ve meslek hastalıkları ile bunlara bağlı gelişen ölümler; kolayca önlenebilir durumlar olmasına rağmen (6), ülkemizde de gittikçe artmaktadır. Yardım ve arkadaşları tarafından yapılan çalışmada (7); ülkemizde 2000 yılındaki iş kazasına bağlı orantılı ölüm hızının 100 binde 224,31 değerinden 290,30'a, aynı tarihlerde meslek hastalığına bağlı orantılı ölüm hızının ise 100 binde 1,84'ten 6,50'ye yükseldiği ifade edilmiştir. Türkiye İstatistik Kurumu 2013 yılı 'İş Kazaları ve İşe bağlı Sağlık Problemleri Araştırma Sonuçları'na göre; toplam iş kazası geçirenlerin yüzde 81,6'sını erkeklerin oluşturduğu, sektörel olarak incelendiğinde, madencilik ve taş ocakçılığ 1 alanında iş kazası geçirenlerin oranı yüzde 10,4 olduğu, sektör bazındaki sonuçlarının 2007 yılı sonuçları ile karşılaştırıldığında iş kazası geçirenlerin payının madencilik ve taş ocakçılığ 1 alanında arttı̆̆ 1 saptanmıştır (8).

Maden ocağı gibi kapalı alanlarda çalışan kişilerin havasız ve toksik maddelere maruz kalmaları sonucu yaşamsal tehlikeye yol açacak herhangi bir travmatik bulgu olmasa da asfiksi ile ölümler görülebilmektedir. Ölüm nedeni, ölüm mekanizması ve orijin tespitinde adli otopsi ve postmortem bulgularla birlikte, olayın oluş şekli ve olay yeri inceleme bulguları da dikkate alınmalıdır (9).

Adli olgu tanımında ifade edildiği üzere iş kazaları ile kaza orijinli ölüm, yaralanma gibi durumlar, sağlık personelinin karşılaştı̆̆1 adli olguyu bildirmesini zorunlu kılan Türk Ceza Kanunu'nun 280. maddesine istinaden bildirimleri gereken adli olgulardır (10). Bu açıdan bakılldı̆̆ında; iş kazası ve meslek hastalığı ile ilişkili olabilecek tüm olguların adli olgu bildiriminin yapılması, ayrıca ölüm olgularında ölüm nedeni ve orijininin tespiti için ölü muayene ve otopsi işleminin mutlaka uygulanması gerekmektedir (6). Bunun sonucu olarak, olası hak kayıları ve mağduriyetlerin önüne geçilecek ve aynı zamanda sağlık çalışanı da sorumluluğunu yerine getirmiş olacaktır.

Çalışma ortamında gerekli güvenlik önlemlerinin alınmaması, hatalı davranışlar, kişisel yetersizlikler, teknik arızalar gibi nedenlerle ortaya çıkan iş kazaları; yaralanmaya bağlı iş gücü kaybı, işlev zayıflaması, işlev kaybı ya da ölümle sonuçlanmasının yanında, üretim sürecini de engellemektedir (11). Ayrıca sanayi, bilim ve teknolojinin gelişmesi sonucu iş kazası veya meslek hastalığına dayanan davalar giderek artmakta olup, buna bağlı olarak işverenin işçi sağlığ1 ve güvenliği önlemlerini alma ve işçinin kişisel değerlerini koruma yükümlülüğü ile oluşan zararları tazmin sorumluluğu da artmaktadır (12).

$\mathrm{Bu}$ çalışmada olguların adli dosyasındaki olay yeri incelemesi ve bilirkişi raporları incelendiğinde; iş güvenliği ve işçi sağlı̆̆ açısından uyulması gereken temel kurallara işçi ve işveren tarafından uyulmaması nedeniyle ölümle sonuçlanan iş kazası meydana geldiği saptanmıştır. Sonuç olarak; işyeri ortamının ve kullanılan araç-donanımın daha emniyetligüvenilir olmasının ve gerekli bakımlarının yapılmasının, işçilerin işleri ile ilgili emniyet ve sağlık, titizlik ve dikkat konularında eğitilmelerinin iş yeri kazalarının önlenmesinde etkili olacağı açıktır.

\section{Kaynaklar}

1. Karakurt Ü, Satar S, Açıkalın A, Bilen A, Gülen M, Baz Ü. Acil tıp kliniğine başvuran iş kazalarının analizi. The Journal of Academic Emergency Medicine 2013;12:19-23.

2. Türen U, Gökmen Y. Türkiye'de meydana gelen iş kazaları sonucu ölümler ile çalışanların yaş faktörü arasındaki ilişki. Sosyal Güvenlik Dergisi 2014;4(1):101-19

3. Can M, Bütün C, Yılmaz R, Beyaztaș FY. İş yerinde beklenmedik bir ölüm: Olgu sunumu. Van Tip Dergisi 2009;16(1):40-2.

4. Türkmen N, Şenel B, Şam B, Üzün İ. İstanbul'da iş kazasına bağlı ölümler. Adli Tıp Dergisi Journal of Forensic Medicine 2005;19(3):29-36.

5. Arslan MM, Eren A, Çekin N. Adana'da iş kazalarına bağlı ölümler. Türkiye Klinikleri J Foren Med 2009;6(2):60-4.

6. Keten A, Karacaoğlu E, Yılmaz H, Karapirli M, Tutkun E, Tümer AR. Meslek hastalıkları ve ölümler. Adli Tıp Dergisi 2011;25(2):107-14. 
7. Yardım N, Çipil Z, Vardar C, Mollahaliloğlu S. Türkiye iş kazaları ve meslek hastalıkları: 2000-2005 yılları ölüm hızları. Dicle Tıp Dergisi 2007;34(4):264-71.

8. Türkiye İstatistik Kurumu'nun 16118 Sayılı 24 Aralık 2013 tarihli Haber Bülteni.

9. Demirci Ş, Doğan KH. Asfiksi türleri ve asfiksi olgularında ölü muayenesi. İçinde: Koç S, Can M. Birinci Basamakta Adli Tip. İstanbul, 2010:38-56.
10. Yılmaz Z. Anayasa Türk Ceza Kanunu Ceza Muhakemesi Kanunu. İlgili Mevzuat. Seçkin Yayınevi, Ankara 2006.

11. Karakurt Ü, Satar S, Bilen A, Açıkalın A, Gülen M. Acil tıp ve iş kazalar1. The Journal of Academic Emergency Medicine 2012;11:227-37.

12. Beyaztaș FY, Alagözlü H, Demirkan Ö. İș kazası olgularının adli tıp yönünden değerlendirilmesi. Adli Tip Derg 2001;15(3):18-24. 